\title{
Surface characterization of rotary-peeled eucalyptus veneers by confocal laser scanning microscopy and surface free energy and contact angle determination
}

\author{
G. Vázquez, J. González-Álvarez, M. S. Freire, J. Santos, \\ R. Uceira \& G. Antorrena \\ Department of Chemical Engineering, \\ University of Santiago de Compostela, Spain
}

\begin{abstract}
Eucalyptus wood wettability was studied using aqueous solutions of chestnut shell and eucalyptus bark tannins as potential components of wood adhesives. The behaviour of both sides of rotary-peeled veneers, the tight and the loose sides, was analysed and lower equilibrium contact angles were found on the loose side, reflecting a higher wettability. In order to evaluate if rotary-peeling had provoked any surface modification responsible of the observed wettability behaviour, the free surface energy of the veneer tight and loose sides was determined using the Owens-Wendt and the van Oss-Chaudhury-Good models. The higher surface free energy values for the loose side justified the better wettability previously obtained. Confocal Laser Scanning Microscopy (CLSM) allowed obtaining topographical images of the material surface, without sample damage, and calculating the crack length and depth together with various roughness parameters. Significant differences between both sides of the veneers have not been found but CLSM has turned out to be a high resolution technique for material surface characterization.
\end{abstract}

Keywords: eucalyptus wood, rotary-peeled veneer, chestnut shell extract, eucalyptus bark extract, wettability, contact angle, surface free energy, confocal laser scanning microscopy. 


\section{Introduction}

Wood-adhesive bond degree depends on several factors such as wood species, physico-chemical wood properties, surface treatments, adhesive properties and glue-line formation conditions.

Christiansen [1] summarised the mechanisms responsible for changes of wood surfaces that may influence wood bonding properties: a) migration of hydrophobic extractives during drying, 2) oxidation, 3) closure of micro-voids in the wood substance which reduces adhesive penetration, 4) acidity or reactivity of extractives affecting the curing time of adhesives and 5) molecular reorientation of functional groups at the surface.

Wettability and wood surface free energy are considered useful parameters to evaluate the bond degree, as provide information on the interaction between adhesives and wood surfaces. Contact angle measurement is the most common technique employed to determine the surface free energy of the solids. Once the contact angles with several probe liquids have been determined, there are various methods for determining the solid surface free energy. Among them, the OwensWendt and the van Oss-Chaudhury-Good (vOCG) methods have been selected in the present work.

Eucalyptus globulus is one of the main forest species in Galicia (NW of Spain), whose wood has a high mechanical resistance that makes it very appropriate for plywood manufacture. However, factories using this wood find serious difficulties due to the high level of rejects, attributed partly to eucalyptus wood characteristics but also to surface changes due to the rotary-peeling process, which affect the interaction with commercial phenolic resins.

In a previous work of the authors [2] the extraction of tannins from chestnut shell and eucalyptus bark extracts and their potential in the formulation of wood adhesives, which could substitute phenolic resins, have been studied.

The aim of this paper is to investigate the effect of rotary-peeling on the characteristics of both veneer surfaces, the tight and the loose sides, by means of contact angle measurement using aqueous solutions of the chestnut shell and eucalyptus bark extracts previously obtained, surface free energy determination and surface analysis by confocal laser scanning microscopy (CLSM). CLSM allows determining the crack length and depth, several roughness parameters and 3D imaging of thick and opaque specimens, such as wood surfaces, without damaging the samples.

\section{Methods}

\subsection{Contact angle determination}

Samples of Eucalyptus globulus rotary-peeled veneers with a humidity of $10 \%$ (wet basis) were used to prepare $2 \mathrm{~cm}$ (length) $\times 2 \mathrm{~cm}$ (width) $\times 1.5 \mathrm{~mm}$ (thickness) wood pieces for contact angle measurements. Contact angle determination was made in the grain direction of the wood according to the sessile drop method using a Dataphysics OCA 15 Plus (Filderstadt, Germany) 
equipment with a video measuring system with a high-resolution CCD camera. The data were analyzed with the Dataphysics software SCA 20.

To compare the wettability of both sides of the eucalyptus veneers, the tight and the loose sides, 10\% (by weight) aqueous solutions of chestnut shell and eucalyptus bark extracts, potential components of wood adhesives, were used. Ten $\mu \mathrm{L}$ drops were added and the variation of contact angle with time was registered till $240 \mathrm{~s}$. For each solution, twelve measurements were done on each side of the veneer.

The surface tension of the extract aqueous solutions was determined by the pendant drop method (with $10 \mu \mathrm{L}$ drops) and using the image analysis software SCA 20 from Dataphysics. Fifteen measurements were done for each solution.

\subsection{Surface-free-energy determination}

The surface free energy of both sides of eucalyptus veneers was determined using the following probe liquids: water, ethilenglycol, diiodomethane and formamide. Five $\mu \mathrm{L}$ drops were added and twelve measurements were carried out on each side of the veneer for each probe liquid.

The equilibrium contact angle used to determine the surface free energy was obtained using the method proposed by Nussbaum [3], based on the determination of the constant wetting rate angle (cwra), which is attained when the wetting rate or $\mathrm{d} \theta / \mathrm{dt}$, being $\theta$ the contact angle, become constant. From these data, the surface free energy was calculated according to the Owens-Wendt and the vOCG models.

Fowkes suggested that the surface free energy of materials $(\gamma)$ could be considered as the sum of various components due to different intermolecular interactions [4]:

$$
\gamma=\sum_{i} \gamma_{i}
$$

The Owens-Wendt model describes the surface free energy, $\gamma_{i}$, as the sum of two components, the dispersive component, $\gamma_{i}{ }^{d}$, and the polar component, $\gamma_{i}{ }^{p}$, according to eqn (2):

$$
\gamma_{i}=\gamma_{i}^{\boldsymbol{d}}+\gamma_{\boldsymbol{i}}^{p}
$$

and eqn (3) allows one to calculate the dispersive and polar components of the surface free energy:

$$
\gamma_{L}(1+\cos \theta)=2 \sqrt{\gamma_{S}^{p} \gamma_{L}^{p}}+2 \sqrt{\gamma_{S}^{d} \gamma_{L}^{d}}
$$

where the subscripts $\mathrm{S}$ and $\mathrm{L}$ represent the solid and the liquid, respectively, and $\theta$, the contact angle. The surface tension and the free surface components for the four probe liquids employed are shown in table 1.

With respect to the vOCG model, the surface free energy is also considered as the sum of two components, the apolar or dispersive component, named the Lifshitz-van der Waals component, $\gamma_{\mathrm{i}}^{\mathrm{LW}}$, which is based on temporary forces of attraction and repellence due to the movement of electrons in molecules, and the Lewis acid-base or polar component, $\gamma_{i}{ }^{\mathrm{AB}}$. The polar component was further 
divided into the Lewis acid, $\gamma_{\mathrm{i}}^{+}$, and Lewis base, $\gamma_{\mathrm{i}}^{-}$, component defined as given in eqn (4).

$$
\gamma_{i}=\gamma_{i}^{\boldsymbol{L} \boldsymbol{W}}+\gamma_{i}^{\boldsymbol{A B}}=\gamma_{\boldsymbol{i}}^{\boldsymbol{L} \boldsymbol{W}}+2 \sqrt{\gamma_{\boldsymbol{i}}^{+} \gamma_{\boldsymbol{i}}^{-}}
$$

To determine the total surface free energy of the solid and its components it is necessary to measure the contact angle of the solid versus at least three liquids according to eqn (5). The apolar and polar components of the surface free energy of the four probe liquids employed are shown in table 2.

$$
\gamma_{L}(1+\cos \theta)=2\left(\sqrt{\gamma_{S}^{L W} \gamma_{L}^{L W}}+\sqrt{\gamma_{S}^{+} \gamma_{L}^{-}}+\sqrt{\gamma_{S}^{-} \gamma_{L}^{+}}\right)
$$

Table 1: $\quad$ Surface tension and surface free energy components for the probe liquids according to the Owens-Wendt model.

\begin{tabular}{|c|c|c|c|}
\hline Probe liquid & $\gamma_{L}(\mathrm{mN} / \mathrm{m})$ & $\gamma^{p}(\mathrm{mN} / \mathrm{m})$ & $\gamma^{d}(\mathrm{mN} / \mathrm{m})$ \\
\hline Water & 72.8 & 21.8 & 51 \\
\hline Diiodometane & 50.8 & 50.8 & 0 \\
\hline Ethylene glycol & 48 & 29 & 19 \\
\hline Formamide & 58 & 39 & 19 \\
\hline
\end{tabular}

Table 2: $\quad$ Surface free energy components for the probe liquids according to the vOCG model.

\begin{tabular}{|c|c|c|c|c|}
\hline Probe liquid & $\gamma^{L W}(\mathrm{mN} / \mathrm{m})$ & $\gamma^{A B}(\mathrm{mN} / \mathrm{m})$ & $\gamma^{+}(\mathrm{mN} / \mathrm{m})$ & $\gamma^{-}(\mathrm{mN} / \mathrm{m})$ \\
\hline Water & 21.8 & 51 & 25.5 & 25.5 \\
\hline Diiodomethane & 50.8 & 0 & 0 & 0 \\
\hline Ethylene glycol & 29 & 19 & 1.92 & 47 \\
\hline Formamide & 39 & 19 & 2.28 & 39.6 \\
\hline
\end{tabular}

\subsection{Confocal laser scanning microscopy (CLSM)}

Samples of the tight and loose sides of eucalyptus veneers, previously coated with gold using a Bio-Rad E5000 Sputted Coater (Hercules, USA) were analysed by confocal laser scanning microscopy using a TCS SP2 Leica microscopy (Mannheim, Germany) and a HC PL APO 10X/0.40 lens. Five random fields or xyz series of $1.5 \mathrm{~mm}$ (length) x $1.5 \mathrm{~mm}$ (width) x $0.5 \mathrm{~mm}$ (thickness) were analysed in each sample. Optical sections were obtained using $2.5 \mu \mathrm{m}$ intervals in the $\mathrm{z}$ direction.

Results were analysed with the Leica Confocal software to obtain topographical images of the surface, 3D topographical surface reconstructions, a roughness profile along a path and the following parameters calculated according to the standard DIN EN ISO 4287:

The roughness index $\mathrm{P}_{\mathrm{a}}$ calculated as follows:

$$
P_{a}=\frac{1}{A} \int_{0}^{A}|Z(x, y)| d A \quad \text { with } \quad Z(x, y)=Z_{i}-\bar{Z}
$$


- The roughness index $\mathrm{P}_{\mathrm{q}}$ (or RMS) calculated as follows:

$$
P_{q}=\sqrt{\frac{1}{A} \int_{0}^{A} Z^{2}(x, y) d A} \text { with } Z(x, y)=Z_{i}-\bar{Z}
$$

- The height of highest peak of the profile (referred to the mean height), $\mathrm{P}_{\mathrm{p}}$.

- The depth of the deepest valley of the profile (referred to the mean height), $P_{\mathrm{v}}$.

\section{Results and discussion}

\subsection{Wettability of eucalyptus wood veneers}

Fig. 1 shows, as an example, the images of a drop of chestnut shell extract on an eucalyptus veneer loose side at the initial a) and final b) stages of the wetting process. The variation of contact angle with time for the aqueous solutions of chestnut shell and eucalyptus bark extracts on the tight and loose sides of eucalyptus veneers is presented in fig. 2. The contact angles shown are the mean value of twelve measurements with each solution and veneer side. Surface tension of chestnut shell and eucalyptus bark extract solutions together with the initial $\left(\theta_{0}\right)$ and final $\left(\theta_{\mathrm{f}}\right)$ contact angles on the tight and loose sides of eucalyptus veneers are given in table 3 .

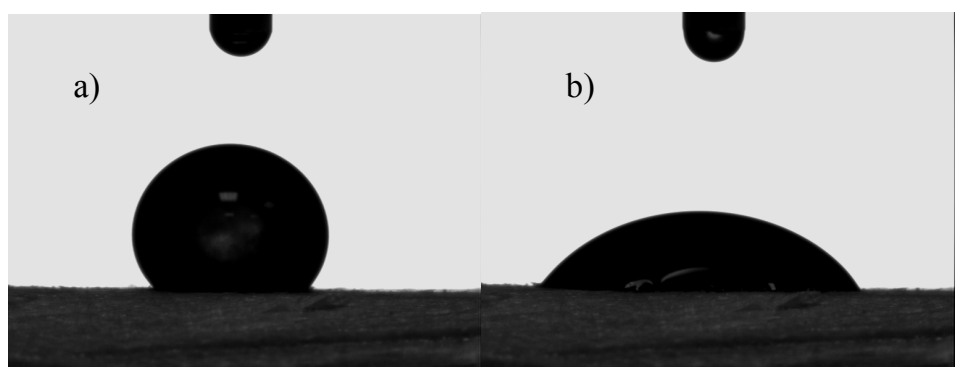

Figure 1: Initial a) and final b) stages in the wetting process of an eucalyptus veneer loose side with a chestnut shell extract solution.

Initial and final contact angles were lower for the eucalyptus bark extract solution on both sides of the veneer, which could be attributed to its lower surface tension, and a better wetting was obtained. On the other hand, initial contact angle was hardly affected by the characteristics of the veneer surface. On the contrary, analysing the time course of contact angles and the final contact angles they are significantly lower on the loose side for both extract solutions. These results revealed that the rotary-peeling process has a marked effect on the wood surface characteristics influencing wood wetting. Shupe et al. [5] also found a better wetting on the loose side of Pinus taeda veneers using water as solvent, however no differences were detected for a phenolic resin due to its high surface tension. 
Table 3: $\quad$ Surface tension of chestnut shell and eucalyptus bark extract solutions and initial $\left(\theta_{0}\right)$ and final $\left(\theta_{\mathrm{f}}\right)$ contact angles on the tight and loose sides of eucalyptus veneers.

\begin{tabular}{|c|c|c|c|c|c|}
\hline \multirow{2}{*}{ Extract } & \multirow{2}{*}{$\begin{array}{c}\text { Surface } \\
\text { tension } \\
\end{array}$} & \multicolumn{2}{|c|}{ Tight side } & \multicolumn{2}{c|}{ Loose side } \\
\cline { 3 - 6 } & $(\mathrm{mN} / \mathrm{m})$ & $\theta_{0}$ & $\theta_{\mathrm{f}}$ & $\theta_{0}$ & $\theta_{\mathrm{f}}$ \\
\hline Chestnut & 60.85 & 148.48 & 78.66 & 149.68 & 59.44 \\
shell & $(0.41)$ & $(6.62)$ & $(14.22)$ & $(11.02)$ & $(14.15)$ \\
\hline Eucalyptus & 51.21 & 138.14 & $\begin{array}{c}65.85 \\
(8.05)\end{array}$ & $\begin{array}{c}134.45 \\
(3.96)\end{array}$ & $\begin{array}{c}57.68 \\
(12.47)\end{array}$ \\
bark & $(0.14)$ & $(8.05)$ & $(8.52)$ & \multicolumn{3}{|c}{} \\
\hline
\end{tabular}

Mean (Standard deviation)

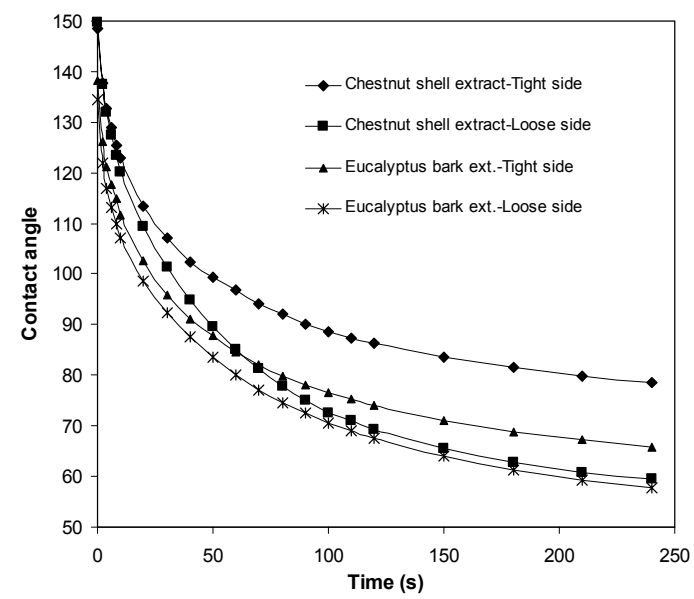

Figure 2: Contact angle versus time for aqueous solutions of chestnut shell and eucalyptus bark extracts on the tight and loose sides of eucalyptus veneers.

\subsection{Surface free energy of eucalyptus wood veneers}

Table 4 shows the constant wetting rate angle obtained on the tight and loose sides of eucalyptus veneers for the different probe liquids employed.

The results obtained for the surface free energy of eucalyptus wood according to the Owens-Wendt model are presented in table 5. The values obtained for the total surface free energy were comparable with those obtained for other hardwoods [6, 7]. On the other hand, it was higher for the loose side of the veneers than for the tight side, which is in accordance with the lower contact angles obtained for the former in the wetting study of eucalyptus veneers with tannin solutions. In both cases, although more significantly for the tight side, the dispersive component was higher than the polar one which is habitual in most polymers [6]. These differences in the surface free energy between both sides of the veneers indicated that the rotary-peeling process might have altered wood surfaces in different way influencing wettability. 
Table 4: Constant wetting rate angle for the different probe liquids on the tight and loose sides of eucalyptus veneers for the calculation of eucalyptus wood surface free energy.

\begin{tabular}{|c|c|c|c|c|}
\hline $\begin{array}{c}\text { Veneer } \\
\text { side }\end{array}$ & Water & Diiodomethane & $\begin{array}{c}\text { Ethylene } \\
\text { glycol }\end{array}$ & Formamide \\
\hline Tight & $63.9(8.75)$ & $61.9(5.32)$ & $26.1(1.87)$ & $25.5(4.15)$ \\
\hline Loose & $50.5(12.42)$ & $58.8(7.65)$ & $21.7(3.46)$ & $25.5(4.15)$ \\
\hline
\end{tabular}

Mean (Standard deviation)

Table 5: $\quad$ Surface free energy components (in $\mathrm{mN} / \mathrm{m}$ ) for eucalyptus veneers according to the Owens-Wendt model.

\begin{tabular}{|c|c|c|c|c|}
\hline Veneer side & $\gamma_{\mathrm{S}}$ & $\gamma_{\mathrm{S}}{ }^{\mathrm{d}}$ & $\gamma_{\mathrm{S}}{ }^{\mathrm{p}}$ & $\mathrm{R}^{2}$ \\
\hline Tight & 45.20 & 29.41 & 15.80 & 0.9451 \\
\hline Loose & 50.72 & 27.33 & 23.39 & 0.9754 \\
\hline
\end{tabular}

The van Oss-Chaudhury-Good (vOCG) model led to the surface free energy data shown in table 6 . The total surface free energy values for both sides of the veneers were slightly lower than those obtained by the Owens-Wendt model. Nevertheless, it was also higher for the loose side and the dispersive component, $\gamma_{\mathrm{s}}{ }^{\mathrm{LW}}$, comparable with $\gamma_{\mathrm{S}}{ }^{\mathrm{d}}$ [4], was also higher than the polar one, $\gamma_{\mathrm{s}}{ }^{\mathrm{AB}}$.

Table 6: $\quad$ Surface free energy components (in $\mathrm{mN} / \mathrm{m}$ ) for eucalyptus veneers according to the vOCG model.

\begin{tabular}{|c|c|c|c|c|c|c|}
\hline Veneer side & $\gamma_{\mathrm{S}}$ & $\gamma_{\mathrm{S}}{ }^{\mathrm{LW}}$ & $\gamma_{\mathrm{S}}{ }^{\mathrm{AB}}$ & $\gamma_{\mathrm{S}}{ }^{+}$ & $\gamma_{\mathrm{S}}{ }^{-}$ & $\mathrm{R}^{2}$ \\
\hline Tight & 42.51 & 27.51 & 14.99 & 6.88 & 8.17 & 0.9820 \\
\hline Loose & 48.30 & 29.28 & 19.00 & 4.02 & 22.47 & 0.9868 \\
\hline
\end{tabular}

With respect to the acid/base character of the wood surface, the basic component was higher than the acid component, which has been also found for other wood species [6]. However, the acid component of the eucalyptus wood is significantly higher than those found for those wood species In addition if the $\gamma_{\mathrm{s}}^{+} / \gamma_{\mathrm{s}}{ }^{-}$ratio is compared between both veneer sides, values of 0.17 and 0.84 were obtained for the tight and loose sides, respectively, which reflects a high significance of the acid component in the tight side with respect to the loose side that can condition wood wettability.

\subsection{Confocal laser scanning microscopy of eucalyptus veneers surface}

Figs. 3, 4 and 5 show, as an example, for one of the fields analyzed by CLSM of an eucalyptus veneer, a 3D topographical surface reconstruction, the topographical image of the surface and the depth profile along a path normal to the fibre length. Although qualitative differences have been found among the fields analysed in the same type of veneer side, the differences were more significant when the fields of tight and loose sides were compared. Tight sides showed smoother and less uneven fields than the loose sides. 


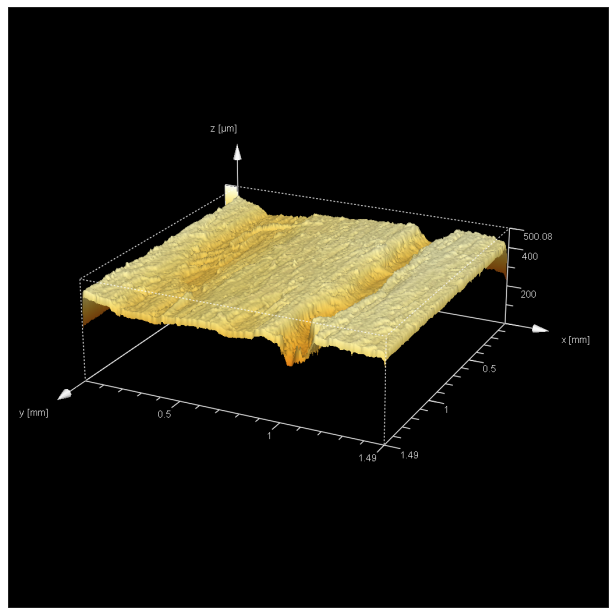

Figure 3: 3D topographical surface reconstruction for one of the fields of an eucalyptus veneer analyzed by CLSM.

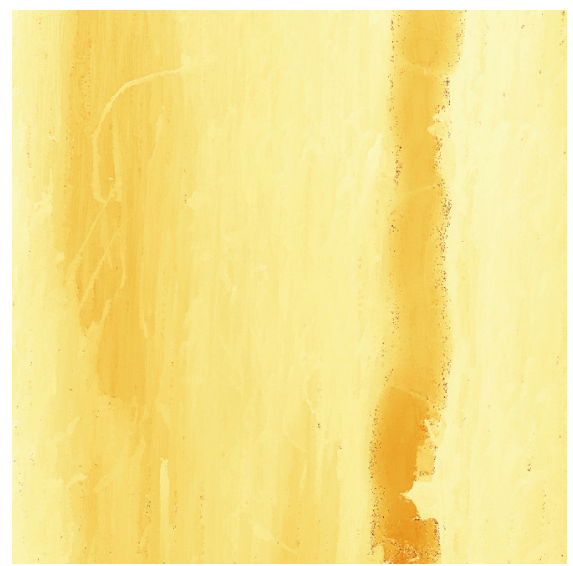

Figure 4: Topographical image of the surface for one of the fields of an eucalyptus veneer analyzed by CLSM.

The results obtained for the different roughness parameters analyzed are presented in table 7. As observed, no significant differences have been found between the values of the different parameters $\left(\mathrm{P}_{\mathrm{a}}, \mathrm{P}_{\mathrm{q}}, \mathrm{P}_{\mathrm{p}}\right.$ and $\mathrm{P}_{\mathrm{v}}$, ) obtained for the tight and loose sides, in contrast with the qualitative analysis. Therefore, although tight and loose sides of the eucalyptus veneers showed differences in the wetting behaviour, it could not be attributed to differences in surface roughness, which suggests that other kind of analysis, such as analysis of surface composition, should be performed. 


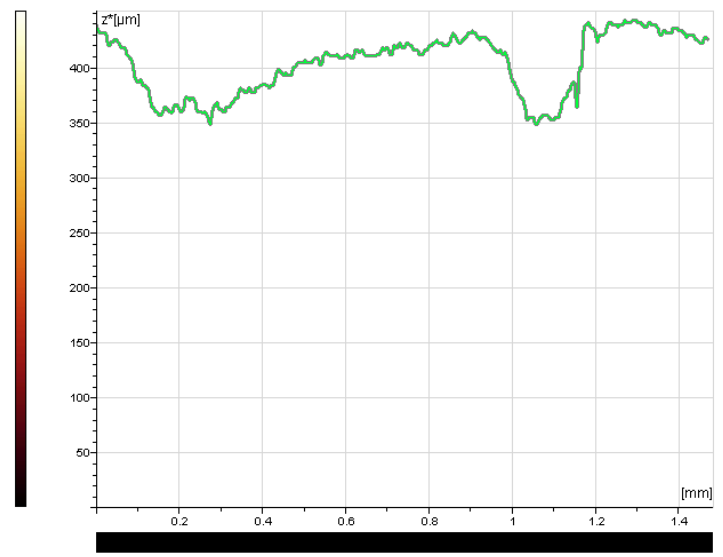

Figure 5: Depth profile along a path normal to the fibre length for one of the fields of a eucalyptus veneer analysed by CLSM.

Table 7: $\quad$ Roughness parameters for the tight and loose sides of eucalyptus veneers.

\begin{tabular}{|l|c|c|}
\hline & Tight side & Loose side \\
\hline $\mathrm{P}_{\mathrm{a}}(\mu \mathrm{m})$ & $29.87(3.02)$ & $30.11(4.68)$ \\
\hline $\mathrm{P}_{\mathrm{q}}(\mu \mathrm{m})$ & $39.02(3.35)$ & $36.18(4.74)$ \\
\hline $\mathrm{P}_{\mathrm{p}}(\mu \mathrm{m})$ & $114.45(11.07)$ & $114.29(11.24)$ \\
\hline $\mathrm{P}_{\mathrm{v}}(\mu \mathrm{m})$ & $385.54(17.60)$ & $388.80(13.22)$ \\
\hline
\end{tabular}

Mean (Standard deviation)

\section{References}

[1] Christiansen, A.W., Effect of ovendrying of yellow-poplar veneer on physical properties and bonding. Holz Roh-Werkstoff, 52, 139-149, 1994.

[2] Vázquez, G., González-Alvarez, J., Santos, J., Freire, M.S. \& Antorrena, G., Evaluation of potential applications for chestnut (Castanea sativa) shell and eucalyptus (Eucalyptus globulus) bark extracts. Ind. Crops Prod., in press, doi:10.1016/j.indcrop.2008.07.004., 2009.

[3] Nussbaum, R.M., Natural surface inactivation of Scots pine and Norway spruce evaluated by contact angle measurements. Holz Roh-Werkstoff, 57, pp. 419-424, 1999.

[4] Etzler, F.M., Characterization of surface free energies and surface chemistry of solids. Contact angle, wettability and adhesion Vol 3, ed. K.L. Mittal, VSP: Utrecht and Boston, pp. 219-264, 2003.

[5] Shupe, T.E., Hse, C.Y., Choong, E.T. \& Groom, L.H., Effect of wood grain and veneer side on loblolly pine veneer wettability. Forest Prod. J., 48(6), pp. 95-97, 1998. 
250 Surface Effects and Contact Mechanics IX

[6] Gindl, M. \& Tschegg, S., Significance of the acidity of wood to the surface free energy components of different wood species. Langmuir, 18, pp. 32093212, 2002.

[7] Meijer, M., Surface energy determinations of wood: comparison of methods and wood species. Langmuir, 16, pp. 9352-9359, 2000. 